\title{
RETROSPECTO SOBRE A EDUCAÇÃO BRASILEIRA
}

\section{Retrospection on the Brazilian Education}

Rosa Lydia Teixeira Corrêa ${ }^{1}$

\section{Resumo}

Neste artigo, a autora faz reflexões sobre a educação brasileira nos níveis básico e superior retomando aspectos dessa história, com o objetivo de demonstrar que esta educação historicamente não tem sido considerada pelo Estado efetivamente como um direito social. Trata-se de um trabalho que intenta sistematizar abordagens feitas em sala de aula em articulação com autores que estudam esse campo. Não se trata de um estudo profundo e pormenorizado. Por isso, tais reflexões estão sendo entendidas em um sentido bastante preliminar.

Palavras-chaves: Educação; História; Direitos.

\section{Abstract}

In this article the author makes reflections on the Brazilian education in the basic and superior levels, retaking aspects of this history with the objective to demonstrate that this education historically has not been effectively considered for the State as a social right. It is concerned with a work that intends to systemize approaches made in classroom in joint with authors who study this field. | A deep and detailed study is not made. Therefore such reflections are being understood in a sufficiently preliminary direction.

Keywords: Education; History; Rights.

1 Doutora em História Econômica, Mestre em Educação pela USP, Professora do Programa de Mestrado em Educação da Pontifícia Universidade Católica do Paraná. E-mail: rosa.correa@pucpr.br. 


\section{Introdução}

A educação é uma prática social que não só simboliza como torna concreta uma dimensão eminentemente humana por meio de seu caráter histórico, que sintetiza o próprio devir do existir do homem tanto sob sua forma sistemática como assistemática. Por ser uma prática humano-social, acha-se intrinsecamente disseminada na sociedade. Por isso é imprescindível enquanto elemento caracterizador de múltiplos modus vivendi de diferentes povos.

Por ser uma prática social historicamente construída, cujo propósito é a formação do sujeito, visa a incutir hábitos e desenvolver condutas, valores, socialmente aceitos em certa civilização e cultura de acordo com o momento histórico vivido e necessidades existentes.

Assim, as características humano-sociais determinam e exigem modos diferenciados de educação de vida para cada povo e, por assim dizer, de cada cultura. De modo amplo, uma sociedade caracteriza-se pelas experiências, práticas educativas que transmite às gerações posteriores, seus valores, costumes, tradições, hábitos que fazem com que sua cultura seja mantida ou modificada dependendo, por isso, de como se desenvolve historicamente cada grupo. Esses grupos podem ser exemplificados pela família, pela igreja, pelos grupos de amigos, pela vizinhança, entre outros.

Importa destacar que nenhuma sociedade é culturalmente superior ou inferior a outra. Há a existência de grupos socialmente diferentes. Por isso, cada cultura só pode ser compreendida a partir e dentro dela.

Observe-se que esta é uma compreensão bastante ampla de educação, já que não se restringe a um tipo específico, mas à educação de modo geral. Nesse sentido, para Brandão (1989), existem tipos diferenciados de educação na medida em que estes se acham estritamente vinculados a um tipo particular de cultura. Assim, existirão tantos tipos de educação quanto forem os de cultura. Mas é não é só isso. Estamos nos educando a todo instante, considerando que a educação encontra-se difusa nas relações e práticas sociais exercitadas pelos diferentes grupos sociais.

Por outro lado, para Saviani (1986), correlacionando educação à cultura, distingue três tipos de educação

Educação escolar", "educação difusa" e "educação popular". A Educação escolar corresponde à cultura erudita. Rege-se por padrões eruditos, sua finalidade é formar o homem "culto" no sentido erudito da palavra, seu conteúdo e sua forma são eruditos; é enfim, o principal meio de difusão da "cultura erudita. Aquilo que estamos chamando, na falta de uma expressão mais adequada, de "educação difusa", corresponde à "cultura de massa". Participa praticamente de todas as características da referida "cultura" de tal 
modo que se pode mesmo dizer que se identifica com ela. Seu principal instrumento de difusão são os meios de comunicação de massa. Enfim, a educação popular corresponde à "cultura popular. (p. 82)

Esse autor vincula ainda educação popular à cultura popular por sua característica animista, realista e prática (SAVIANI, 1986, p. 81-2).

O que chama atenção na definição de Saviani é a relação que estabelece entre educação e cultura. É diferente daquela defendida por Brandão. Nesta ela é própria de certo grupo, significando, por assim dizer, aquilo que o caracteriza, que o torna peculiar. Em Saviani, a cultura tem também fins mercadológicos, ou seja, vincula-se estreitamente a idéias e valores, enfim, interesses que se deseja sejam veiculados por entre um contingente amorfo de indivíduos (SAVIANI, 1986).

Freire (1987), diferentemente de Saviani e avançando para uma compreensão mais abrangente de educação, entende-a como sinônimo de conscientização. Valores, atitudes, comportamentos só serão válidos se estiverem correlacionados à libertação que significa a tomada de consciência do sujeito sobre o seu estar aqui e agora no mundo que o rodeia. Deve, pois, significar instrumento de libertação na sua relação com o mundo, para poder, assim, interferir sobre ele.

Quer em seu sentido formal quanto informal, por achar-se disseminada na sociedade, a educação se presta a certo tipo de serviço no sentido tanto de libertar como de oprimir pessoas. Eis aqui seu caráter político. A educação informal e a formal estão disseminadas na sociedade por meio de diferentes instituições e é por estas que realiza sua função política, tendo como protagonistas diferentes sujeitos sociais. Entre estas instituições está a Igreja que, enquanto tal, e por sua natureza, cumpre uma finalidade doutrinária do ponto de vista social. Esta finalidade é diferente da educação que se desenvolve no interior da escola.

É preciso, por isso, compreender por um lado, como a educação escolar tem sido propiciada à grande parcela da população brasileira correlatamente ao fato de que ela pode tornar-se instrumento de libertação, levando em conta a realidade educacional do país historicamente construída.

Assim, parece-me importante realizar uma reflexão retrospectiva sobre a educação brasileira. Isto será feito levando em conta o seu caráter formal/escolar concomitantemente à sua compreensão como uma problemática social que se manifesta histórica e processualmente.

Com efeito, falar da educação brasileira é abordar um tema de bastante complexidade devido às ambivalências que ela apresenta no decorrer de sua história. Neste sentido, ela se confunde com as próprias contradições da sociedade capitalista brasileira e que apresenta indeléveis marcas de uma configuração social hierarquizada em decorrência de sua composição classista. 
Assim, a educação brasileira além de não poder ser entendida fora de sua relação com aquela sociedade, não pode, por outro lado, deixar de ser tratada sem que aspectos históricos sejam retomados no sentido de que ela possa ser compreendida na atualidade. Desse modo, é nesse sentido que procuraremos, do ponto de vista metodológico, fazer uma apreciação dessa educação em diferentes níveis. Não se trata, por isso, de fazer uma análise pormenorizada de cada um deles, mas apresentar uma visão que consideramos panorâmica, a fim de que tenhamos, grosso modo, um entendimento genérico sobre ela. No item seguinte, denominado de a educação escolar básica, este tipo de educação estará sendo objeto de apreciação pela especificidade que guarda em relação à educação superior, que será objeto de apreciação no item posterior, o de número três.

\section{Sobre a educação escolar básica}

No universo da educação escolar brasileira, a partir da Lei de Diretrizes e Bases, de 20 de Dezembro de 1996, a Educação Básica é composta pela Educação Infantil, Ensino Fundamental e Médio. Situar essa organização tornase importante para que possamos entender sua composição para, desse modo, poder referi-los em relação à problemática social de oferta que permite possibilidades ou não de acesso e de permanência no sistema de ensino e, conseqüentemente, a repercussão na relação entre sujeito e sociedade brasileiros.

O descobrimento e a colonização do Brasil por Portugal no século XV deve ser entendido no contexto da expansão marítima e mercantilista capitalismo mercantil, demarcado pelo expansionismo marítimo e comercial europeu, dos séculos XV e XVI.

A descoberta e a incorporação do temitónio brasileiro, no âmbito da civilização ocidental e cristã, são partes de desdobramento da Revolução Comercial, dos séculos XIV e XV, que deu origem à formação sócio-cultural capitalista. A europeização da América Portuguesa, como de resto de toda América Latina, esteve nosúltimos séculos ligada estritamente à expansão universalista do capitalismo que aos poucos vai deixando de ser europeu para ser mundial, sem perda de seus mecanismos oniginários de dominação e exploração (PAIVA, 1982; p. 9).

Nesse sentido, é possível falar de outro formato de globalização do qual são demandadas formas de relações que se estabelecem entre colonizador/ colonizado; formas de dominação que têm como referência a catequese realizada pelos padres católicos pertencentes à Companhia de Jesus, que aportou no então Brasil (1749), então colônia portuguesa, com o primeiro Governador Geral Tomé de Souza. Catequese essa que, segundo Paiva (1982), representava, 
Toda a ação pastoral da igreja: a doutrinação propriamente dita, a pastoral litúrgico-devocional, o comportamento das pessoas e das instituições eclesiásticas. Trata-se, na verdade, da catequese tal qual se realizou efetivamente e não de uma catequese teórica, universal, uniformemente transmitida para todos os povos, indiferentemente. (p. 13)

Para Paiva, ainda,

A catequese, tal qual a definimos acima, não pode ser tomada como tarefa de uma Igreja distinta da gente portuguesa que aqui se assentou, senão como uma das expressões mais características de sua cultura. A distinção, que hoje fazemos, entre Estado e Igreja, era impensável no século XVI: Estado e Igreja se fundiam numa sociedade única, "sui generis". Cristianização e aportuguesamento são tarefas sinônimas, indissociáveis e identificáveis entre si. ... (p.13).

Nesse período, Xavier (1994) nos lembra que

Instalou-se aqui um capitalismo rudimentar e primitivo através do que se convencionou chamar de economia agrário colonial exportadora, uma forma primitiva de dominação capitalista, diferente da européia, que assumia formas cada vez mais avançadas, na sua ruptura com passado escravista e feudal (XAVIER, 1994, p. 30).

Abordar a educação brasileira requer falar da participação jesuíta nos seus primórdios, sem o que se torna difícil compreendê-la em seu conjunto. Essa importância deve ser estabelecida a partir das relações travadas no interior da colônia e que se caracterizaram por relações de dominação de diferentes ordens, tais como: imposição cultural (valores, costumes, tradições) para o que a Igreja e a religião e o seu fundamento moral tiveram papel preponderante. Ressalte-se, ainda, que as formas de dominação também podem ser entendidas do ponto de vista simbólico, no sentido da interpretação proposta por Bourdieu (1989), enquanto violência não física, já que imposta por meios de mecanismos sutis desenvolvidos sem visibilidade aparentemente imediata.

Entender a escola como dado da cultura portuguesa colonial e não brasileira é imperioso para compreendê-la no seu contexto e formas de relações sociais que ai se estabelecem bem como o papel reprodutor que ela exerce. Nesse universo, lembrar do sentido elitista das escolas e dos colégios que eram destinados a poucos contribui para rememorar sobre uma mentalidade que tem a corte portuguesa como eixo sociopolítico fundamental. Desse modo, a relação da escola com o restante da composição maior da sociedade colonial é bastante distanciada. 
Segundo Paiva (2000, p. 20), o formalismo pedagógico jesuíta operava no sentido de empreender uma educação voltada para não fazer isso ou aquilo cuja finalidade seria frear a natureza rebelde do homem, significando possibilitar-lhe fugir de tudo aquilo que pudesse representar pecado, mentiras, injúrias, lugares perniciosos.

A Companhia de Jesus foi expulsa de Portugal e de seus domínios no ano de 1759, como parte da política de modernizadora do então Ministro de Portugal, Sebastião de Carvalho e Mello, o Marquês de Pombal. No entendimento desse ministério, os jesuítas representavam o conservadorismo do qual Portugal precisava distanciar-se, a fim de que pudesse adentrar a modernidade a qual o restante da Europa já abraçara e, principalmente, reforçar o poder do Estado com o fito de atingir propósitos econômicos e políticos ${ }^{2}$.

No campo educacional, a reforma do Marquês de $\mathrm{Pombal}^{3}$ desenvolveuse pormeio das chamadas Aulas Regias ${ }^{4}$, na tentativa de preencher o vazio deixado pela escolarização jesuíta. As Aulas Régias representavam uma escola que

era uma unidade de ensino com um professor. O termo escola era utilizado com o mesmo sentido de cadeira, ou seja, uma Aula Régia de Gramática Latina, ou uma Aula de Primeiras Letras, correspondia, cada uma, a uma cadeira específica, o que representava uma unidade escolar, uma escola. Cada aluno freqüentava as Aulas que quisesse, não havendo articulação entre as mesmas. De modo geral, chamavam-se mestres aos que ensinavam as primeiras letras e professores aos de todas as demais cadeiras. (CARDOSO, 2004, p. 187)

2 Cunha refere três razões que motivariam Portugal à expulsão dosjesuítas de suas colônias: primeiro: incentivo às manufaturas na metrópole pela criação da reserva de mercado nas colônias, com a proibição das manufaturas que começavam a existir nas regiões das minas, no Brasil; segundo: incentivo à cumulação de capital público e privado, pela concessão do privilégio de monopólio do coméncio de certos bens a companhias formadas na metrópole e nas colônias; terceiro: a substituição das ideologias onientadas para uma sociedade feudal, por outras, orientadas para uma sociedade capitalista (1986, p. 41).

3 A Reforma dos Estudos empreendida por Pombal foi realizada em diferentes etapas, segundo Cardoso (2004). "A primeira fase, iniciada com o Alvará de 28 de Junho de 1759, caracterizou-se pela Reforma de Estudos Menores, em Portugal que eram estudos de primeiras letras e das cadeiras de humanidades."

A segunda fase deu-se com a Reforma de Estudos Maiores, a partir da Lei de 06 de novembro de 1771, quando se realizaram os estudos específicos da Universidade de Coimbra.

4 O sistema implantado com a Reforma dos Estudos Menores de 1759 baseava-se, portanto, nas Aulas de primeiras letras e nas Aulasde humanidades, que eram denominadas de maneira geral de Aulas Régias. É oportuno assinalar que no Despotismo Ilustrado a palavra régio tem um caráter ambíguo, porque ao mesmo tempo em que remete à figura do monarca, reiterando uma tradição absolutista, que persiste período afora, representa também o avanço que o termo traz, pela contraposição à tradição de ensino por parte da Igreja. Nesse caso, as Aulas Régias significavam as Aulas que pertenciam ao Estado e que não pertenciam à Igreja. (....) (Cardoso, 20004, p. 182). 
É entendimento comum na historiografia da educação brasileira que essa fase de nossa educação, embora possa ser caracterizada como aquela na qual o Estado português toma para si a responsabilidade para com a educação, no entanto suas ações não foram suficientes para preencher a lacuna deixada pelos jesuítas.

Entendo que a histónia humana é processo e não sucessão de fatos isolados. Processo esse que, dependendo da profundidade de sua incidência, tende a deixar marcas profundas para a posteridade. Por isso, do ponto de vista educacional, desde a expulsão dos jesuítas, a elite política dirigente não foi capaz de construir uma base sólida e, por isso, consistente nesse campo. A lógica que se tem sido seguida, grosso modo, desde então, mantém um dos aspectos daquele núcleo que caracteriza a relação dominador X dominado, colonizador X colonizado, quando mantém em suas bases a idéia que à subalternidade devem ser destinadas pouca oferta de vagas na rede escolar pública, professores mal pagos e pouco capacitados e infra-estrutura escolar deficitária ${ }^{5}$.

A vinda da família real portuguesa para o Brasil em 1808 representou não só um fato político de grande envergadura em função das razões que provocaram esse episódio, entre eles o endividamento a que estava submetido Portugal em relação à França, como também no que esse fato trouxe de conseqüências para a então colônia brasileira. Nesse sentido, situam-se as realizações que aqui foram feitas, substancialmente no campo educacional, cultural e científico, ainda que tenham sido realizadas com o fito de proporcionar condições para a estada da realeza na colônia. A historiografia registra que no período imperial, as realizações aqui empreendidas o foram sob as bases do pensamento utilitarista justamente devido aos fins com que são realizadas obras educativas e culturais. Elas não tiveram um fim social, pois não havia intenção de educar e desenvolver culturalmente a maioria da população brasileira de então.

A sociedade brasileira a partir os primeiros trinta anos do império passa por significativas mudanças que servem de exemplo para falar de indicadores de desenvolvimento econômico de maneira geral, tais como: a criação do Banco do Brasil (1851) e Sociedades Anônimas; a inauguração da primeira linha telegráfica no Rio de Janeiro; em 1853, a fundação do Banco Rural hipotecário; em 1854 é inaugurada a primeira linha de estrada de ferro, entre outros. Esse

\footnotetext{
5 Mesmo com a criação dos grupos escolares cuja estrutura arquitetônica e física visava propiciar a alunos e professores plenas condições de trabalho pedagógico, no Paraná que, seguindo o exemplo de São Paulo, quando da inauguração de primeiro Grupo Escolar, o Xavier da Silva (1903), não havia professores capacitados o suficiente para atender à demanda escolar. Em estudos que realizei, constatei que, no interior daquele Grupo, funcionou, no período de 1904 a 1912, uma escola promíscua (classe composta por meninos e meninas em níveis de estágio de aprendizagem diferenciados e regida por uma professora).
} 
crescimento resulta de parceria comercial com a Europa, da importação de maquinário e equipamentos assim como de idéias que circulavam no meio intelectual formado por integrantes das classes dominantes e médias.

Foram essas idéias importadas, segundo aquela autora, Cardoso (2004), que impulsionaram propostas de reformas de diferentes instituições, já que era preciso "liberar o trabalho, a consciência e o voto", mostra do pensamento liberal reinante de que se fazia preciso elevar e/ ou igualar o Brasil aos patamares dos países modernos. Essas idéias sedimentam pontos comuns entre liberais e cientificistas, quais sejam: abolição dos princípios aristo cráticos; separação da Igreja do Estado; secularização dos cemitérios; abolição da escravidão; libertação da mulher por meio da instrução; crença na educação como chave para resolver os problemas fundamentais do país. Todo esse ideário repercute no campo da organização escolar no que refere às críticas sobre a sua ineficiência e, conseqüentemente, proposição de reformas.

Mas é durante o Império que a existência do sistema público e privado, ainda que não fosse possível falar de sistema educacional, começou a existir, principalmente, no que pese à educação de primeiras letras.

(...) merece registro que, no Brasil em geral, havia um incentivo do estado para a proliferação do ensino particular, tanto no período em que ainda era América Portuguesa ou já como país independente, durante o Império. Traduzia-se essa política de diferentes meios, como por exemplo o descaso e a omissão quanto aos assuntos da educação pública, a necessidade de dividir a tarefa com a sociedade, a prática das subscrições populares para arrecadar fundos, o incentivo e a parceria com as sociedades e as associações voltadas para a promoção da instrução. (Cardoso, 2004, p. 183)

Azanha (2004), diz que

Com a vinda da Família Real já no início do século XIX, a educação brasileira recebeu um grande impulso no que diz respeito ao ensino superiornecessário para a formação de quadros, mas a educação popular permaneceu relegada a um segundo plano. (p. 69)

Embora o Ato Adicional de 1834 tenha sido uma medida importante porque descentralizadora esbarrou na incapacidade das províncias em assumirem efetivamente os encargos com a educação escolar primária em face de dificuldades financeiras em decorrência dos baixos percentuais de arrecadação de impostos, aquele autor nos ajuda ainda a refletir sobre a educação no período Imperial, acrescentando que 
naquele período, o quadro geral foi sempre o mesmo: escassez de escolas e de mestre no ensino primário. Com relação ao ensino médio, exclusivamente propedêutico ao ensino superior, prevaleceram as aulas avulsas apenas acessíveis as às classes abastadas. É verdade que houve tentativas notáveis de estruturação de cursos regulares com propósitos amplamente formativos e não apenas preparatórios. O colégio Pedro II, os Liceus da Bahia e de Pernambuco e algumas outras poucas escolas são exemplos desse esforço, mas isso não foi suficiente para a alteração do quadro geral. Mais para o final do Império, até mesmo as escolas afetadas pela mentalidade vigente, que nos estudos de grau médio apenas uma preparação para o ensino superior. Não faltaram, contudo, principalmente na segunda metade do século XIX, tentativas de reforma, mas a tendência de multiplicação de aulas avulsas e dos exames parcelares prevaleceu, e nas vésperas da República houve esforços no sentido de modificação desse quadro. (AZANHA, 2004, p. 70)

Desse modo, a proliferação paulatina de escolas privadas desde 0 Império se dá devido à tímida participação do Estado em face à crescente necessidade de segmentos sociais que vêem a escolarização como necessária à inserção de sujeitos no processo civilizatório moderno. A inserção social por meio do trabalho se torna elemento central no processo de desenvolvimento urbano e industrial crescente. Como exemplo, refiro iniciativas de imigrantes de diferentes etnias ${ }^{6}$ que criaram suas próprias escolas justamente pela ausência de escolas públicas nos locais nos quais se achavam instalados, destacadamente em Núcleos Coloniais. A privatização amplia-se também na medida em que as relações sociais capitalistas se intensificam e a educação começa a ser vista como fator de geração de capital.

A educação brasileira tem sido destacada como estando constantemente em crise, que pode ser descrita como de qualidade, de oferta/investimento, de formação de professores, só para citar alguns exemplos. Destaque desse tipo também pode ser verificado nos dias de hoje, quando comumente ouvimos falar de falta de vagas nas escolas públicas, de má preparação de professores, de quando alunos nas diferentes regiões do país são aprovados sem que tenham domínios básicos da leitura e da escrita, quando há ausência de infra-estrutura básica nas escolas, principalmente daquelas que se acham localizadas nas periferias de grandes centros urbanos.

Se o quadro educacional escolar durante o Império não foi alentador e pode ser configurado como de crise, contudo na Primeira República ${ }^{7}$, em-

\footnotetext{
A exemplo, os alemães e italianos.

O período político denominado historicamente no Brasil de Primeira República tem início em 1889 com a Proclamação da República por meio de um golpe de estado do qual fizeram parte militares ideologicamente positivistas, grupos de intelectuais e setores da oligarquia cafeicultora desejoso de fazer parte da composição do poder político nacional.
} 
bora não se tenha avançado substancialmente em termos práticos substanciais, tentativas de melhorias foram empreendidas. Exemplo concreto foi a política de implantação dos Grupos Escolares cuja matriz está no Estado de São Paulo e que serviu de modelo para outros Estados, entre eles o do Paraná ${ }^{\text {. }}$ Embora tenham sido idealizados em prol de atender aos segmentos populares, não lograram total êxito nesse sentido.

A Carta Constitucional de 1891 selou a República ao estabelecer a organização federativa para os Estados até então províncias, que desde então passam a gozar de mais autonomia política e administrativa, resultando, segundo Dallari (1989), "de uma convergência momentânea de forças heterogêneas a até contraditórias", militares positivistas, representantes das oligarquias cafeicultora e açucareira.

Por outro lado, segundo ainda esse autor, foi o positivismo, por meio de Benjamin Constant, que fomentou a República. Ele advogava a idéia de construção de uma sociedade pacífica, justa e ordeira como horizonte para o progresso.

Não seria demais referir que para o cenário de instituição de ações republicanas no campo da educação se inclui o pensamento de Rui Barbosa, por meio dos seus famosos pareceres, para quem a "instrução do povo é vista como requisito fundamental da ordem e do progresso e estaria inevitavelmente ligada à vitalidade das instituições" (BARBOSA, 1946, I, p. 132, In: NASCIMENTO, 1997). Para Rui, a educação se constituiria em instrumento de modemização por excelência. Segundo ele, abrir escolas é fechar cadeias. A ignorância traz a ausência de percepção de dever. Razão pela qual a educação deveria ser cultivada.

Visão de que na escola se amoldaria, em cada um, aquele comportamento condizente com a lei e ordem estabelecida, é um estímulo muito forte ao pedagogismo conservador. Ao mesmo tempo em que se diminui a criminalidade e se obtém a segurança, incrementa-se a produtividade e economizamse recursos públicos que em caso contrário deveriam ser empregados e na assistência social. O "ensino integral estaria apoiado em três conteúdos: intelecto, físico e no sentimento. (NASCIMENTO, 1997)

A formação do intelecto estaria calcada no conhecimento científico visando a formação do espírito científico. "Este é visto como condição para 0 desenvolvimento da capacidade produtiva nacional, fundamentado na riqueza e soberania da Nação e na felicidade das pessoas". A ciência tem um lugar preponderante a ocupar no futuro das novas gerações:

8 Vernesse sentido os estudos de SOUZA, Rosa Fátima de. Templos deCivilização: a implantação da escola primária graduada no estado de São Paulo (1890-1910). São Paulo: Fundação Editora da UNESP, 1998. BENCOSTA, M. L. A. Arquitetura e Espaço Escolar: reflexões acerca do processo de implantação dos Grupos Escolares de Curitiba (1903-1928). Educar em Revista, Curitiba, 2001. 
Todo futuro de nossa espécie, todo governo das sociedades, toda prosperidade moral e material das nações dependem da ciência, como a vida do homem depende do ar. Ora, a ciência, é toda a observação, toda exatidão, toda verificação experimental. Perceber os fenômenos, discernir as relações, comparar as analogias e as dessemelhanças, classificar a realidade, e induzir as leis, eis a ciência; portanto o alvo que educação deve ter em mira. Despertar na inteligência nascente as faculdades cujo concurso se requer nesses processos de descobrir e assimilar a verdade, é o a que devem tender os programas e os métodos de ensino. (.....). (NASCIMENTO, 1997, p. 51 e 52)

A educação física seria introduzida nas escolas com a finalidade de promover o desenvolvimento harmonioso do ser humano. A educação do sentimento seria obtida por meio da música e do desenho. Pela via da cultura musical, o indivíduo conseguiria expressar seus sentimentos. A música elevaria e purificaria as almas. Apesar da importância da música, ela não tem mais significado do que o desenho. Para ele, ainda,

(....) o desenho é um dote acessível a todos os homens, e não um privilégio dos artistas por vocação e profissão; (...) Que, na ordem pedagógica, bem como na ordem histórica, o desenho precede a escrita. Que o seu ensino deve principiar desde os primeiros passos da criança na cultura do espírito, isto é, desde a entrada no kindergarten; (...), longe de sobrecarregar o programa, ele o ameniza, longe de retardá-lo ó lhe faz ganhar tempo; longe de dificultar os outros estudos, facilita-os e auxilia-os en ormemente; (....) Que é um elemento essencial no cultivo das faculdades de observação, de invenção, de assimilação e reten ção mental; (...) Que a sua gen eralização como disciplina inseparável da escola popular é uma das forças mais poderosas para a fecundação do trabalho e o engrandecimento da riqueza dos Estados. (NASCIMENTO, 1997, p. 54)

Destaque-se que, para Rui Barbosa, o respeito às etapas naturais do desenvolvimento dos sujeitos se faz concomitantemente à semelhança da evolução humana, ênfase da educação dos sentidos e para os sentidos. A importância decorre da observação, da reflexão, do raciocínio indutivo, da atividade do aluno durante o processo de aprendizagem, do método experimental. São pontos fundamentais de sua metodologia, inspirado em Pestalozzi, Froebel, Bain e Spencer (NASCIMENTO, 1997, p. 61). Sem dúvida, muitos dos princípios defendidos por Rui Barbosa foram incorporados às, digamos, políticas pedagógicas dos grupos escolares. 
Segundo Azanha (2004), em termos de reformas educacionais

A República, nos seus inícios, foi pródiga em reformas - Benjamin Constant (1890), Epitácio Pessoa (1901), Rivadávia Correia (1911), Carlos Maximiliano (1915) -, mas foi preciso esperar até a década de 20 para que, realmente, 0 debate educacional ganhasse um espaço social mais amplo. Foi nesse período que a questão educacional deixou de ser apenas tema de reflexões isoladas e de discussões parlamentares para ser percebida como problema nacional, isto é, como problema afeto ao próprio destino da nacionalidade. (p. 71)

Além dessas Reformas, outras foram levadas a efeito na década de 20: em 1920, no estado de São Paulo, por Sampaio Dória; em 1922, no do Ceará, por Lourenço Filho, comissionado ao governo do Ceará pelo estado de São Paulo; em 1927, no estado de Minas Gerais, por Francisco Campos; em 1928, no Distrito Federal, por Fernando Azevedo, vindo de São Paulo a convite da Prefeitura do Rio de Janeiro e, finalmente, em 1928, no estado da Bahia, por Anísio Teixeira.

Essas reformas corroboram a idéia de que

A proposta republicana partilhava, com as demais, certas tendências da época: ser antecipatória, na medida em que a escola era pensada como parte de uma totalidade, de um projeto político que se antecipava às reivindicações e outros setores da sociedade, ser dualista, pois, embora fosse preciso fornecer ensino a toda à sociedade, não se tratava de oferecer todo o ensino para toda a sociedade; ser preocupada com a extensão da escola elementar, reivindicando a alfabetização das massas. Assim, o projeto republicano pensa e oferece a escola nos moldes dos cafeicultores, antes que outras diferentes camadas sociais a reivindicassem nos seus próprios moldes; propõe educação elementar e profissional para as massas e educação científica para as elites "condutoras do processo" e reivindica ampla educação popular. (HILSDORF, 2006, p. 61-2)

Aliás, a Primeira República, destacadamente nos anos vinte, foi fértil em agitações decorrentes de setores desejosos de que a sociedade brasileira desenvolvesse-se autonomamente dos pontos de vista político, econômico e cultural, a fim de que pudesse de fato constituir-se numa nação capaz de definir seus rumos, levando em conta sua identidade a ser sumamente cultivada. Nesta linha está a Semana de Arte Moderna de 1922.

Na Primeira República, a educação escolar pode ser considerada como um bem diferente do que até então tinha sido realizado, principalmente em vista de sua propagação em bases modernas e científicas. O cientificismo e a modernização são bandeiras liberais que irão demarcar e definição do Estado laico, o que trará para a Igreja Católica a necessidade de reorganização educa- 
cional e de recomposição de estratégias políticas no sentido, por exemplo, de garantir o espaço para o ensino religioso nas escolas, a posteriori.

Os anos de 1930 a 1945 seriam caracterizados novamente pela idéia de reconstrução da nação que não foi levada a cabo na Primeira República. Urgia então realizar o que deixaram em aberto os republicanos. No que pese à revolução de 1930, ela incorporou bases sociais e de aspirações heterogêneas, tais como as elites civis, a velha oligarquia, a nova conjuntura do movimento operário, as classes médias urbanas, os tenentes, como assinala Hilsdorf (2006). Lembra essa autora ainda que a revolução de 1930 só pôde sair vitoriosa em decorrência do acordo entre esses segmentos, representados pelo chamado "Estado de Compromisso", sob a liderança de Getúlio Vargas, por meio da promoção do capital nacional (idem). Entre as ações do governo provisório estão a criação do Ministério da Educação e Saúde Pública, a Reforma Francisco Campos (1931-1932), composta por vários Decretos, entre eles, o da Organização do Ensino Superior e regime universitário.

Nesse cenário, o Manifesto da Educação Nova de 1932 para Azanha (2004) resultou de debate entre educadores partidários do Movimento pela Educação Nova, considerado como "um documento que constitui marco histórico" na educação brasileira. Para ele, "a mais nítida e expressiva tomada de consciência da educação como um problema nacional".

Importa referir que o segundo período Vargas (1937-1945), além de conter o registro sobre o desenvolvimento de um projeto nacional civilizador, foi substancialmente um tempo em que grande parte da população imigrante foi duramente perseguida no sentido de ajustar-se aos novos ideais.

A educação escolar em parte desse período está caracterizada principalmente por meio das Leis Orgânicas do Ensino editadas pelo então Ministro Gustavo Capanema, de 1942 a 1946, no período do Estado Novo. As Leis Orgânicas incorporaram princípios defendidos pelos escolanovistas que apregoavam ser a educação instrumento do Estado na preparação do homem para agir na sociedade e nação brasileiras, face o seu potencial de desenvolvimento produtivo ${ }^{9}$.

No governo Juscelino Kubitschek de Oliveira (1956-1961) serão desenvolvidas as políticas educacionais que, historicamente, acham-se vinculadas à idéia de planejamento entendido como fator e/ou mecanismo de desenvolvimento social no Brasil, no universo da compreensão de recuperar cinqüenta nos de desenvolvimento do Brasil em cinco, de Planos de Metas.

9 Sobre a relacão da Escola Nova Liberal como Estado novo, ver a autora referida citando a contraposição feita por Marta Carvalho, que aponta os traços comuns defendidos pelo Estado Novo e a Escola Nova por meio de prescrições, tais como: padronização da programação curricular e da arquitetura escolar, do controle do recreio e disciplina, da adoção de classes homogêneas e do método único de leitura, de clubes agrícolas, exposições, excursões e jornais escolares, do escotismo, do cinema e rádio educativos, de grêmios e caixas escolares. 
Nesse sentido, a educação é em si potencial de capital, chamado por Horta (1982) como capital humano. Neste enfoque, a educação também é fator de bem-estar da população mundial. Ela está fortemente vinculada à razão econômica, portanto ao avanço e conseqüente fortalecimento das relações sociais de produção no mundo capitalista. Na medida em que a educação se vincula enquanto política social ao desenvolvimento econômico, as políticas distributivas ficam em segundo plano. Na verdade elas só adquirem importância quando se constituem em ameaça ao desenvolvimento econômico.

Nessa linha de entendimento, nas décadas de 60 e 70, podem-se destacar dois grandes planos importantes. O Plano Decenal para década de 1966a 1976. Este plano introduz a conceituação econômica no plano da educação e esta como geradora de capital humano e o Plano Setorial de 1972 a 1974, baseado na idéia de que a educação é fator de progresso tanto individual como da nação.

Visava estender a matrícula de $1^{\circ}$. grau a $80 \%$ das crianças na idade de escolarização (7 a 14 anos); eliminar 0 analfabetismo na faixa dos 15 aos 35 anos da idade; expandir os sistemas treinamento e retreinamento, proporcionar terminalidade do ensino de $2^{\circ}$. grau visando à formação de técnicos em nível médio; expandir a oferta ensino superior, especialmente nas áreas técnicas, da formação magistério e das ciências da saúde, acelera a reforma da universidade. (cfr. FREITAG: 1980, p. 100)

A idéia de planejamento ganha corpo ${ }^{10}$ não só nas instâncias políticas decisórias, mas também nos meios educacionais. Nos meios educacionais de modo geral e em nível pedagógico em particular, era preciso planejar a fim de que eficientes e eficazes se tornassem os processos de ensino/aprendizagem e a produção escolar. O planejamento educacional atinge a escola. Assim, ele se tornará, principalmente após os anos setenta, elemento não só burocrático e de controle do trabalho pedagógico como de pretensa eficácia da instituição educativa. Pode-se dizer, diante disso, que o planejamento se constitui numa referência básica por ser um marco no tocante às reformas sociais.

10 O Plano Qüinqüenal de 1975 a 1979. Continha o entendimento da educação como contribuição para a realização do projeto nacional. Seus objetivos eram: despertar as vocações desde o nível do ensino fundamental; expandir a oferta de matrículas para o ensino fundamental par atingir 100\% de escolarização na faixa etária de 7 a 14 anos até 1980, expandir a oferta de vagas no ensino médio e superior, capacitar recursos humanos no sentido de garantir a melhoria da produtividade de ensino; promover a interação escola e comunidade; implantar e expandir os campi universitários, eliminar gradativamente o analfabetismo de adolescentes e adultos (faixa etária de 15 a 35 anos); prestar assistência técnica e financeira a instituições particulares de ensino. (Idem, 103). 
O movimento que acompanha a dinâmica da escola privada em direção às classes médias e ricas e destas para aquelas com maior intensidade no tempo histórico se dá a partir dos anos setenta do século vinte, com a chamada democratização do acesso. A escola pública passa a ser organizada em primeiro e segundo graus ${ }^{11}$, com a supressão dos exames de admissão ${ }^{12}$ que, segundo críticos, se constituía num mecanismo de seleção. Mas a democratização do acesso pode ser entendida tanto pela política de ampliação da ofertas vagas na escola pública, quanto pela formação de professores. Daquela perspectiva, ou seja, da ampliação da oferta de vagas, se dá estimulada e, ao mesmo tempo, justificada pelo crescimento urbano industrial que proporcionou o deslocamento de um contingente populacional importante do campo para os principais centros produtores do país, tais como: São Paulo, Rio de Janeiro, Belo Horizonte e Porto Alegre, e outros centros menores, naquela época, como Belém, Curitiba, Goiânia, Brasília, etc.

Como dissemos, a democratização do acesso à escola pública se deu pela ampliação da ofertas de vagas resultante de uma política que não privilegiou a construção de novos edifícios, mas a ampliação de turnos de até cinco, incluindo o noturno ${ }^{13}$. Dessa realidade fizeram parte classes com séries iniciais de escolarização, em especial as primeiras, com alunos em torno de cinqüenta. Nesta condição achavam-se crianças em maior número sem nenhuma experiência escolar anterior. Esse é um exemplo do que se convencionou denominar de massificação do acesso e que neste trabalho chamaríamos de democratização concentrada.

A idéia de democratização concentrada se justifica pela política de ampliação centralizada administrativamente, pois na proporção em que as vagas foram aumentadas e, obviamente, as matrículas também, o tempo de permanência diária foi reduzido em função da criação de novos turnos, não sendo, por isso, criadas novas unidades administrativas. Grosso modo, o número de pessoal técnico-administrativo permaneceu o mesmo, havendo somente a contratação de novos professores. Neste aspecto em particular está o outro ponto nodal das iniciativas democratizantes do Estado no interior do regime de exceção que também referimos anteriormente e sobre o qual agora discorreremos.

11 Nesse sentido ver a Lei 5.692/71.

12 Exame anual realizado ao término das séries iniciais do ensino primário, sendo condição para o ingresso no antigo ginásio.

13 A ampliação de turnos se deu com base na utilização da estrutura então existente em muitas escolas, com a construção de salas onde havia espaço para tanto ou com a criação de anexos, termo usado para designar uma unidade escolar à parte, composta de número de salas variáveis e banheiro subordinada administrativamente a uma escola maior. 
Historicamente, os sistemas público e privado de ensino incorporam, grosso modo, uma característica peculiar: a de representarem a dualidade do sistema de ensino brasileiro e, portanto, de sua educação. Mas o que isso significa? Que existe um sistema de ensino para os ricos e outro para os pobres. Mas essa dualidade também apresenta suas peculiaridades históricas. Se a escola privada de modo geral, principalmente a escola católica, nasce com o objetivo de servir aos ricos, e a àqueles que mesmo não o sendo podiam pagar por ela, destacadamente aquelas vinculadas a Congregações Religiosas ${ }^{14}$, com o passar do tempo, mesmo essa característica se mantendo, haverá uma inversão em relação a níveis de ensino diferenciados. A escola privada para os ricos será a destinada aos níveis que compõem a educação básica, passando a haver uma inversão em termos de ensino superior, quando em sua maioria elas são destinadas à grande parcela da classe trabalhadora, que não tem acesso à grande parte das universidades públicas de boa e excelente qualidade.

A formação de professores pra a educação escolar pra as séries iniciais do primeiro grau, certamente o pilar de qualquer politica educacional, foi reduzida para três anos por meio de cursos de magistério nos Institutos de Educação. De modo geral, nesses cursos não havia preocupação com uma formação voltada para a compreensão consistente dos processos de desenvolvimento cognitivo, afetivo, psicomotor e social das crianças, bem como interrelacionado a esses processos o domínio de procedimentos de alfabetização e de suas inter-relações histórico-sociais que remetem às condições objetivas dos alunos. Entre as conseqüências dessa formação estavam a dificuldade de alfabetizar, o que resultou em alunos que, na em sua grande maioria, sabiam grafar palavras por meio de cópia, porém não as decodificavam, o que gerou reprovações em massa. Como conseqüência, havia alunos que permaneciam anos sucessivos nas séries iniciais ou aqueles que eram promovidos sem saber ler, embora grafando palavras corretamente por meio do mecanismo da cópia. Esse é um exemplo de como o processo de escolarização inicial tornou-se massificado em nome do acesso democrático.

Não seria demais dizer que essa é uma face da racionalidade presumivelmente eficiente, segundo a mentalidade politicamente dominante ${ }^{15}$.

Em contrapartida essa é, por conseguinte, uma faceta que permite a interpretação de termos como democratização e massificação, que se justificariam quando se trata de oportunizar escolarização à grande parcela da população. Os anos setenta particularmente desde a promulgação e implantação da

14 Entre elas podemos referir a Congregação de São José de Chambéry, que fundou colégios nas regiões Sul e Sudeste, destinados para a educação de moças pertencentes à elite cafeicultora.

${ }^{15}$ Ver nesse sentido COVRE. M. L. A fala dos homens: análise do pensamento tecnocrático brasileiro pós-64. São Paulo: Brasiliense, 1986. 
Lei 5.692/71, certamente se constitui num marco a partir do qual a escola pública brasileira tornar-se-ia um espaço destinado exclusivamente ao segmento social trabalhador que não possui condições de dar a seus filhos melhores ofertas educacionais.

Não seria demais assinalar nesta passagem que a democratização nesta etapa da educação brasileira apresenta uma ambivalência que pode ser demarcada pela seguinte compreensão: primeiro o estado ao garantir o acesso à grande parte da população urbana em idade escolar comporta-se como liberal, por ser democratizante, oportunizador, concessor de direitos. Segundo, por tornar a democratização sinônimo de massificação, ele atua como neoliberal ao distanciar-se de suas efetivas responsabilidades para com uma educação escolar cidadã.

À noção de democratização se vincula a de eficiência, eficácia e funcionalidade do sistema de ensino, tornando-se, portanto, um imperativo racionalizá-lo em todas as suas formas e níveis, visando a atingir um tipo de racionalidade que torne de qualidade. Idéia advinda da teoria geral de administração de empresas sob a ótica das influências de Frederic Taylor e Henri Fayol (início do século XX), cuja preocupação recai sobre o processo produtivo, por meio do planejamento e do controle de trabalho. Influências também advindas de campos teóricos, tais como: escolas de relações humanas, psicologia comportamental e funcionalismo, segundo a lógica empresarial que toma como pressuposto orientações que visam: prever, organizar, comandar e controlar.

Esse modelo adquire substância no universo do discurso desenvolvimentista pós-ditadura militar, relacionado à baixa qualidade do sistema educacional. Este precisa ser fator de desenvolvimento econômico, já que sua ineficiência é elemento de entrave para o desenvolvimento econômico do país. Concomitantemente a solução também passa ser tecnológica, que acompanha a etapa capitalista monopolista que requer mão-de-obra tecnicamente qualificada no bojo do Estado interventor e planejador.

A concepção de aprendizagem que ganha corpo se faz no sentido de modificação de comportamento. Para tanto, a avaliação se torna fundamental. É quando ela começa a ser entendida como fator de geração de qualidade de ensino. Mais tarde, a partir de meados de 1990, principalmente depois da promulgação da Lei de Diretrizes e Bases da Educação Nacional 9394/96, se tornará efetivamente integrante da cultura escolar numa concepção mais ampla, pois deixará de restringir-se ao âmbito pedagógico, para constituir um mecanismo de busca de qualidade nos diferentes âmbitos da instituição escolar. Permanecerá, no entanto, à revelia das posições teóricas críticas sobre ela, servindo muitas vezes como instrumento de seleção, coerção, de dominação e de diferenciação negativa quando usada, por exemplo, para justificar demissão de professores, principalmente na iniciativa privada. 
Os modelos avaliativos presentes nas escolas brasileiras nos anos de 1970 esteve alicerçado no modelo educativo à compreensão skineriana sobre as influências que o indivíduo recebe do meio ambiente no sentido de sua determinação em termos de condicionamentos e com o pensamento positivista na medida em que a mente não é capaz de captar a realidade objetiva e reagir sobre ela; modelos de instrução programada.

Acompanha o imenso desgaste que essa escola pública passou sofrer a partir de então, a desvalorização do exercício do magistério destacadamente o destinado à escolarização básica. Os professores desde então são submetidos a longas jornadas de trabalho, a fim de que possam auferir a um salário que lhes permita sobreviver com dignidade. Há situações em que ultrapassam quarenta horas semanais. Além disso, têm que se submeter a certas condições decorrentes das desigualdades sociais e que repercutem no interior da escola pública, como a violência.

Embora a democratização tenha sido uma medida há muito esperada, no entanto, o modo como foi entendida não fez dela um ideal positivo em razão de ter gerado conseqüências até hoje sentidas na escola pública. Ao mesmo tempo em que representou uma política de ampla participação na educação escolar propiciada por parte do Estado, concomitantemente foi retirado dos segmentos sociais que a ela tiveram acesso o direito de usufruir dela com qualidade por meio de professores mais preparados e melhor remunerados, classes com números de alunos conforme requerem teorias e princípios pedagógicos e escolas melhor equipadas e com manutenção, às quais fazem jus sujeitos que pagam impostos devidamente.

De modo geral esse é o modelo de escola pública que temos presenciado com raras exceções de mudanças em termos operacionais, ainda que tenhamos tido uma nova Lei educacional vinte e cinco anos após a Lei de 1971. Avançamos em termos de relações democráticas institucionais, sem dúvida, como temos avançado que pese a estudos sobre a educação brasileira, porém pouco temos efetivamente respondido às reais exigências que a realidade educacional tem manifestado. Exemplos disso constam da Nova Lei da Educação Brasileira 9394/96, e que podemos referir resumidamente com a finalidade deste pensamento: o princípio de gestão democrática ao qual se articula o de autonomia para as instituições de ensino elaborar seus projetos pedagógicos. É uma questão que atinge tanto a educação básica como a superior. Isso aponta para a idéia de descentralização e se aproxima da de flexibilidade própria do formato de Estado neoliberal no bojo do qual essa Lei foi gestada e aprovada.

A Lei 9394/96 trouxe a prerrogativa dos sistemas de ensino se organizarem em séries ou ciclos, flexibilização que permite lidar de modo mais brando com a problemática da retenção, principalmente nas séries iniciais, 
mas que não tem incidido sobre suas causas. Até porque não está ao alcance da lei educacional dirimir problemas decorrentes da pobreza, por exemplo, que repercutem sobremaneira na sala de aula. Outro aspecto seria a implementação de uma política séria de formação de professores que contemplaria tanto a formação acadêmica por meio de cursos que têm essa finalidade como a formação contínua e aqui há respaldo da Lei. Esta, concomitantemente ao desenvolvimento de políticas sociais de outra natureza (moradia, saúde, emprego, saneamento básico), concorreria para dirimir fatores que dificultam tornar a educação pública elemento de melhoria, na medida em que escola em muito se penaliza dos efeitos da pobreza.

A nova Lei da Educação também nos agraciou, talvez com um dos seus pontos mais fortes, o da avaliação da qualidade da educação em seus níveis fundamental e superior, a partir da qual políticas têm sido desenvolvidas, tais como: o Sistema de Avaliação da Educação Básica (SAEB), o Exame Nacional de Cursos hoje ENADE e o Exame Nacional do Ensino Médio (ENEM).

Além das mudanças propriamente ditas em termos da Composição em dois grandes Níveis Escolares: Educação Básica (Educação Infantil, Ensino Fundamental e Ensino Médio), e Educação Superior, essa LDB não possibilitou transformações no interior do sistema de ensino, a não ser no que pese ao cumprimento dos duzentos dias de efetivo trabalho escolar (Lei 9394/96, art.24 - Inciso I). Por outro lado, ela nos permite depreender nas entrelinhas desse artigo que o tempo de permanência na escola indica qualidade de ensino.

\section{Sobre a educação superior}

Fazer ainda que uma breve apreciação sobre a educação superior no Brasil não se constitui tarefa fácil pelo fato de que podemos deixar de referir aspectos importantes que não se nos ocorre neste momento. Por isso, o objetivo neste item não é o de fazer uma retomada minuciosa sobre esse nível de educação até porque muitos estudiosos já o fizeram com brilhantismo ${ }^{16}$, razão pela qual a abordagem aqui realizada será sucinta e, ao mesmo tempo, genérica.

Com efeito, a educação superior no Brasil tem sua gênese, segundo Cunha (1986), com os colégios jesuítas ${ }^{17}$ que, no Brasil colônia, tinham a função de formação do clero para dar prosseguimento ao trabalho de catequi-

16 Entre outros, ver, nesse sentido, o que chamo de tríade sobre o Ensino Superior no Brasil, CUNHA, Luiz Antônio. A universidade crítica: o ensino superior na república populista. Rio de Janeiro: F. Alves, 1989; CUNHA, Luiz Antônio. A universidade reformanda. Rio de Janeiro: F. Alves, 1985; CUNHA, Luiz Antônio. A universidade temporã: o ensino superior da colônia à era de Vargas. Rio de Janeiro: Civilização Brasileira, 1986.

17 Colégios jesuítas funcionaram na Bahia, Recife, Olinda, Piratininga, Rio de Janeiro, São Luis, e em Belém. 
zação dos índios. Nesse sentido, além da finalidade específica, destinavam-se a uma parcela muito pequena da população, assim sendo, a uma elite.

A forma e o modo como a educação e, de modo geral, o ensino superior em particular desdobram-se no Brasil-colônia está intimamente vinculada à política colonizadora dos portugueses.

A compreensão da educação só poderá completar-se articulando os momentos de desenvolvimento sócio-cultural com as estruturas educacionais implantadas. Ambos os fenômenos são complementares: educação e expansão dos mecanismos de dominação do capitalismo no Brasil. (PAIVA, 1982, p. 9)

Nos tempos de Pombal, a educação superior teve ínfimas formas de desdobramento por meio do Seminário de Olinda e de iniciativa dos padres franciscanos. Nunca foi interesse de Portugal edificar em suas colônias e, no caso do Brasil, instituições de educação superior, destacadamente universidades. Temia a metrópole que a colônia tivesse acesso às idéias iluministas e que poderiam representar ameaça ao domínio Português. Convém ressaltar que 0 ensino superior no Brasil tem sua origem diferenciada de toda América espanhola, que criou sua primeira Universidade em 1538 (Universidade de Lima no Peru).

O ensino superior no Brasil ganhou relativo impulso com a vinda da família Real para o Brasil em 1808, quando foram criados cursos: de medicina, cirurgia, agronomia, desenho técnico, entre outros, em instituições isoladas, visando a atender às necessidades da corte e, ao mesmo tempo, compor 0 quadro burocrático da administração imperial (CARVALHO, 1996). Este quadro foi particularmente composto por bacharéis assim como o da magistratura, cuja finalidade foi a de dar condições para a instalação e permanência na colônia, da família imperial e o restante da sua composição.

Mas não só a burocracia do Estado nascente carecia de profissionais sistematicamente formados. Também necessitava deles a produção de bens simbólicos para consumo das classes dominantes. Assim é que além dos novos cursos superiores militares e de medicina, e dos antigos, de filosofia e de teologia, confinados então aos conventos episcopais, foram criados cursos superiores de desenho, história, música. O curso de arquitetura, sintomaticamente localizado na academia de Belas Artes, também desempenhava a função de formar especialistas na produção de bens simbólicos. Mas de certo, foram os cursos de direito os mais importantes dos que cumpriram essa função, pois os bacharéis tinham, na atividade cotidiana de elaborara, discutir e interpretar a leis, a atarefa principal de formular e renovar as ideologias que legitimavam as relações de dominação mantidas e dissimuladas pelo aparelho jurídico. (CUNHA, 1986, p. 68) 
Importa destacar que a vinda da Família Real para o Brasil, do ponto de vista político, representa não só a transferência da composição do Estado Português para o Brasil, mas para esse autor a configuração da origem do Estado Nacional brasileiro, portanto anterior a 1822, quando a independência é proclamada.

José Murilo de Carvalho (1996) faz sobre esse período uma das mais belas interpretações quando ressalta que as iniciativas em prol do ensino superior, com a vinda da Família Real para o Brasil, permitem, a partir da formação de quadros jurídicos, culminar na formação de uma ilha de letrados num mar de analfabetos. Neste particular, refere-se ao grande número de analfabetos existentes na colônia, composto pela população mais pobre e, por conseguinte, a grande maioria. A educação superior, mais uma vez, destina-se a uma parcela ínfima da população que a historiografia convencionou chamar de parcela dominante econômica e politicamente. A vinda da Família Real nos legou uma composição de educação superior que somente sofrerá modificações a partir dos anos de 1930, posteriormente à Primeira República.

A retomada desses aspectos, digamos assim, mais rudimentares da educação brasileira em relação ao ensino superior, já nos permitem inferir que, em suas origens, esse tipo de educação não esteve a serviço de uma causa ou de um interesse social mais amplo. Esta é uma característica que irá, aliás, acompanhá-la no decorrer do tempo.

No período imperial, o ensino superior quase que não apresentou alterações em relação àquele período no qual a corte portuguesa esteve instalada no Brasil, ou seja, entre 1808 e 1822. Com o Ato Adicional de 1834, o ensino superior, sob o princípio da descentralização, definiu as responsabilidades com o ensino em duas esferas: uma nacional e outra provincial. A primeira correspondia a estabelecimentos criados por meio de lei de assembléia geral e o segundo por leis emanadas das assembléias provinciais (CUNHA, 1986). Para esse autor ainda,

A esfera nacional tinha grande importância, pois possuía o poder de conferir títulos acadêmicos dotados de validade jurídica em todo país. $O$ diploma de ensino secundário da esfera nacional, o do colégio Pedro II, dava direito de ingresso em qualquer esfera de grau superior, enquanto os egressos das escolas secundárias da esfera provincial eram obrigados à prestação de exames de habilitação junto àquelas escolas. (p. 86)

Até o fim do império, entretanto, a situação do ensino superior permaneceu praticamente inalterada e foi durante a Primeira República que teve 
sua maior expansão, porém no setor privado, tempo no qual foram criadas as primeiras instituições ${ }^{18}$ desse gênero, chamadas de universidade, porém sem que tenham frutificado.

Interessa-nos particularmente referir sobre a expansão do setor privado em nível de oferta do ensino superior na Primeira República, em decorrência da prosperidade econômica resultante do crescimento da cafeicultura que possibilitou o desenvolvimento manufatureiro, por meio principalmente do fomento à indústria paulista, que trouxe em seu bojo o nascimento de uma classe operária e média. A indústria requeria formação de mão-de-obra qualificada. Por outro lado, os latifundiários desejam ver seus filhos formados doutores.

Nesse cenário, o poder central permitiu a criação de cursos superiores pela iniciativa privada por meio da criação de inúmeras faculdades e da facilitação do acesso ${ }^{19}$. Esta fase do ensino superior se justificaria do ponto de vista ideológico pela bandeira da liberdade de ensino levantada e defendida pelos liberais e positivistas ${ }^{20}$. Estes últimos viam na desoficialização do ensino uma maneira de criar mais condições para ampliar as possibilidades de profissionalização, bem como torná-la livre.

18 A Primeira Universidade criada no Brasil como tal foi de Manaus, no Amazonas, em 1909, em 1911 a de São Paulo, em 1912 a de Curitiba e posteriormente as Universidades do Rio do Janeiro, criada em 1920, a de Minas Gerais, em 1927.

19 Ver nesse sentido as duas obras de Cunha referidas na bibliografia deste trabalho.

${ }^{20}$ O Positivismo foi a corrente filosófica que mais influência teve do ponto de vista político e socioeducacional no Brasil em boa parte do Império Brasileiro, e destacadamente na durante toda a primeira república. "O positivismo, de acordo com Augusto Comte, não é uma corrente filosófica entre outras, mas a que acompanha, promove e estrutura o último estágio que a humanidade teria atingido, fundado e condicionado pela ciência. Comte usa o termo filosofia com o mesmo sentido que lhe atribuía Aristóteles, isto é, como definição do sistema geral de conhecimento humano. É o termo positivo significando o real por oposição ao quimérico, o útil por oposição ao ocioso, a certeza em oposição à indecisão, o preciso em oposição ao vago. O termo significa, ainda, o contrário de negativo e indica a tendência em substituir sempre o absoluto pelo relativo. Finalmente, traduz a proposta de organização moral e intelectual da sociedade." (SIMON, 1986, p. 120). Comte afirma ter "descoberto a lei dos três estados, uma grande lei fundamental. Para ele o espírito dos indivíduos, assim como a espécie humana e a própria ciência, passam por um movimento histórico que atravessa um estado teológico ou fictício, estado metafísico ou abstrato, antes de chegar ao terceiro e último estado, o positivo, termo fixo e definitivo no qual o espírito humano encontra a ciência." (idem, p. 121) O princípio básico da ciência é a observação. Segundo Torres (1957), as primeiras manifestações da doutrina comteana no Brasil se deram nos meios matemáticos e depois militares. Posteriormente estenderam-se para o campo do direito. Além de ter-se constituído numa filosofia do século XIX, ela ultrapassa os limites da compreensão matemática para tornarse uma concepção de mundo. No Brasil Benjamin Constant é o seu mais ilustre representante, desde a fundação do Apostolado Positivista por Miguel Lemos e Teixeira Mendes em 1857. 
A liberdade de promoção do ensino superior por parte da iniciativa privada segue então duas vertentes, uma política e outra econômica, a primeira pela via ideológica e a segunda pelo desenvolvimento econômico. Uma e outra permitiram que segmentos das classes médias e altas tivessem seus interesses atendidos na medida em que desejavam obter diploma de curso superior, o que representaria a conquista de mais status justamente porque a obtenção do diploma permitiria ser bacharel ou doutor. Note-se que este será ao longo da história do acesso ao ensino superior um elemento de composição, já que ele funcionará como impulsionador em direção à universidade, grosso modo falando, por todos os segmentos sociais, que se encontrem minimante em condições que concorrer a uma vaga nesse nível de ensino.

$\mathrm{O}$ que distingue a fase expansionista do ensino superior privado da Primeira República da que temos hoje são dois aspectos: o primeiro de ordem política que se situa em nível dos embates parlamentares em torno da supressão dos privilégios concedidos, por exemplo, aos egressos do Colégio Pedro II, como vimos no item anterior, e instituição dos exames vestibulares como requisito para o ingresso no ensino superior; e o segundo de ordem social, caracterizada pelo acesso ao ensino superior privado de jovens da classe alta e média. Este segundo aspecto se constitui num diferencial que se observará na expansão do ensino superior nos fins da década de 1990 e início do século XXI no Brasil, quando segmentos populares serão substancialmente os que engrossarão as fileiras do acesso à escolarização superior privada e de qualidade duvidosa em sua grande maioria.

Mas se a Primeira República não logrou se caracterizar como um tempo de grandes realizações positivas em nível de ensino superior ${ }^{21}$, o período que lhe sucedeu pode ser considerado, sem sombra de dúvida, como de importantes realizações do estado nesse campo.

As lutas sociais ${ }^{22}$ que marcaram o fim da Primeira República deixaram para a etapa posterior muitos desafios, sobretudo sociais, ao lado do movimento cultural provavelmente mais significativo daquele período, a Semana de Arte Moderna de 1922 e, dez anos depois, o Manifesto da Educação Nova de 1932. Referir sobre essa participação da sociedade civil na luta por um Brasil melhor, que buscasse constituir-se política, ideológica, cultural e economicamente independente, permite-nos dizer que a universidade esteve de fora dessa efervescência, ainda que ela seja passível de críticas, no sentido de que dela deixaram de erigirem-se vozes por um país igual, justamente porque ela não existia, já que tão tardia foi sua constituição de fato.

21 Talvez a mais importante delas tenha sido a medida tomada por meio do Decreto 5.616 de 28/ 12/1928, que atribui autonomia administrativa, didática e financeira às Universidades criadas nos estados, ao mesmo tempo em que restringia a criação de universidades privadas.

22 Movimento Operário e o Tenentismo, este de composição diversa, foram movimentos importantes que marcaram os meados e o fim da Primeira República. 
Com efeito, dentre os anos da Era Vargas, que se estenderam por quinze anos, destacadamente em 1931 pudemos constatar, por meio do Decreto de 19.851 de 1931, a instituição do Estatuto das Universidades Brasileiras, o que passaria e representar o controle do Estado da gestão administrativa e da política, ao definir padrões de organização e de funcionamento. Ressaltese que esta medida vem acompanhada da criação do Ministério da Educação. Neste aspecto em particular, entre outros, está o exercício da cátedra que passou a ser vitalícia (CUNHA, 2000).

Embora o contexto político em termos de administração central fosse efetivamente centralizador, no Estado de São Paulo, em 1934, foi criada a Universidade de São Paulo pela conjunção de várias faculdades e escolas superiores.

Por outro lado, certamente uma das participações mais importantes no âmbito da educação brasileira e da superior em particular deva ser demarcada pela contribuição reivindicatória do movimento estudantil por meio da União Nacional de Estudantes (UNE), que, inspirado na Carta de Córdoba, em dezembro de 1938, elaborou no $2^{\circ}$ Congresso Nacional de Estudante, uma proposta de organização e gestão da universidade pública e democrática. Essa proposta tornar-se-ia importante do ponto de vista histórico pelo conteúdo que apresenta, entre outros, os de ser a universidade aberta a todos; exercício da liberdade de pensamento, de cátedra, de imprensa e crítica; eleição de reitores e diretores pelo corpo docente e discente, entre outros. Ressalte-se que a carta de Córdoba seguia influenciando o movimento estudantil em diferentes Estados até o início dos anos de 1960, quando ainda não eclodira 0 Golpe de Estado.

As décadas de 1950 e 1960 são importantes para a educação superior, justamente por ser ao longo delas que as exigências em tomo desse nível de ensino far-se-ão com mais vigor, em decorrência da intensificação do processo urbano-industrial. Desenvolvimento e modernização são palavras que irão demarcar esse período, pelo fato não só de indicarem possibilidades de progresso econômico como de exigência de formação de mão-de-obra qualificada segundo os patamares da organização internacional do trabalho, correspondentemente a políticas de internacionalização de capital. Segundo esse espírito, já havia sido criado em 1947 o Instituto Tecnológico de Aeronáutica (ITA), considerado um centro formador de excelência seguindo modelo norteamericano. Mais tarde, em 1962, a criação da universidade de Brasília sob o regime de fundação veio ampliar as possibilidades de formação acadêmico/ científicas na Região Centro-Oeste.

Os anos sessenta foram particularmente singulares no universo da educação brasileira principalmente em relação ao ensino superior, como veremos a seguir. $\mathrm{O}$ núcleo fundamental desse período é definido pelo apogeu do 
Regime Militar e seu corolário: a repressão à participação política e manifestação ideológica aos seus opositores, principalmente nos dez primeiros anos do regime (GERMANO , 1994).

Em meio à repressão política, a reforma do ensino superior empreendida por meio da Lei de $n$. 은 540/68, além afirmar a legitimidade desse grau de ensino desde a universidade, foi instrumento de desarticulação política pela introdução entre outros do sistema de crédito, da instituição de departamentos como mecanismo de controle do discente e discente, respectivamente. A matrícula sob o regime de créditos talvez seja aquela que trouxe conseqüências mais drásticas para movimento estudantil brasileiro, uma vez que os alunos poderiam agora matricularse em diferentes disciplinas em diferentes horários e turmas. Aparentemente essa medida poderia parecer benéfica para os alunos na medida em que poderiam organizar seus horários acadêmicos como lhes aprouvesse. Entretanto, o que parecia facilidade era um modo de desarticulação política, pois estando estes matriculados em horários com turmas e pares diferentes, as condições de articulação política se tornariam ínfimas. Esta foi sem dúvida uma medida inteligente e eficaz da reforma do ensino superior do regime de exceção. O movimento estudantil não só enfraqueceu de lá para cá, como naquele período foi calado. Ele esteve em franco movimento de proposição da melhoria do ensino superior durante todos os três primeiros anos daquela década, prática que vinha sendo feita desde os fins dos anos de 1930, quando UNE empreendeu ações reivindicando a democratização da educação superior. Outra medida importante da reforma do ensino superior do período ditatorial foi a extinção do sistema de cátedra em voga desde os anos trinta.

Para Cunha (2000), o período ditatorial foi contraditoriamente aquele no qual a universidade e o ensino superior tiveram maior impulso. Foi um tempo de investimento na pós-graduação, da extinção do regime de cátedra, da definição e instituição de princípios e normas para a organização das universidades federais, tempo no qual elas sofreram grande expansão pelo Decreto 53/66, bem como a unidade entre ensino e pesquisa concentrando-os como condição para o desenvolvimento de pesquisa básica de modo a comporem um sistema comum para toda a universidade e a criação de uma unidade comum de formação de professores para o ensino secundário e da formação de especialistas em assuntos pedagógicos.

Intimamente articulada à idéia de desenvolvimento e de modernização, a pós-graduação no Brasil, ao mesmo tempo em que foi uma iniciativa que logrou resultados positivos em curto espaço de tempo, representa uma face contraditória do regime. 
No bojo do processo de reforma universitária, as universidades brasileiras lograram instituir todo um novo segmento do sistema de ensino e de pesquisa - os programas de pós-graduação - inspirados no modelo norte-americano. Essa experiência suscitou interesse por parte de administradores públicos e de acadêmicos de vários países pela rapidez com que foi efetivada (uma década), pela amplitude (todas as áreas de conhecimento) e pela legitimidade (grande receptividade nos diversos setores intra e extra-acadêmicos). (idem, p. 183)

Mas a reforma da educação superior incorporaria outras ambivalências. Uma delas é que a expansão desse nível de ensino nesse período não se deu somente por meio da interiorização que a organização federativa das universidades propiciou, mas também por sua privatização, que será fortemente influenciada nos anos noventa e início do século XXI.

Convém mencionar que universidades públicas estaduais, as do Estado de São Paulo em particular, desde este período, têm desempenhado um importante papel, na formação em nível de pós-graduação ao propiciarem 0 fomento à pesquisa pelo incentivo e investimento na formação de pesquisadores por meio de programas de mestrado e de doutorado. Este cenário fez com que a partir principalmente dos meados dos anos de 1980 se percebesse um quadro no qual despontavam duas Universidades: a de São Paulo e a Universidade Estadual de Campinas como instituições cujo investimento na pós-graduação lhes permitiu a vanguarda e consolidação da pesquisa acadêmica no país. Embora essa seja uma conquista importante no âmbito de ensino superior, ela também incorpora uma perspectiva bastante elitista, na medida em que esses centros de excelência tornar-se-ão também centros acolhedores de grande parcela da elite economicamente dominante desejosa de auferir da participação na formação tanto em nível de graduação como de pós-graduação. Característica esta que irá marcar grande parte das instituições públicas federais, às quais têm acesso substancial parcela da população mais abastada em fase de ingressar no ensino superior. Neste ponto em particular manifestase outro aspecto da dualidade do sistema de ensino brasileiro nesse nível, que é diferente daquele que acontece, grosso modo, na educação fundamental e que se revela num sistema público para pobres. No ensino superior público, portanto, essa situação se inverte.

A última década do século XX e primeiros anos do século XXI trazem importantes elementos para refletirmos sobre o ensino superior no bojo da educação brasileira, justamente pelo fato de que ela representa não só um marco de concessão à privatização da oferta desse nível de ensino, por parte do Estado, como também porque essa permissão articula-se ao princípio de democratização, na medida em que grande parte das camadas populares passa a ter cesso a esse nível de ensino. Assim, quando o acesso ao ensino superior é permitido pela classe dominante a essa par- 
cela da população brasileira, ele é feito pela via particular que hoje compõe grande parte de um mercado de oferta de vagas que convencionei denominar de varejão do ensino superior. Esta definição se direciona para um campo de instituições privadas de ensino superior bastante diferenciada no que pese a organização e funcionamento que são definidos pelos seus fins ${ }^{23}$.

Cunha (2004), falando sobre a nova organização das Instituições de ensino superior pós nova LDB 0394/96, por meio dos decretos 2.306/97 e 3 . 860/01, assim se manifesta:

A organização acadêmica das IES também foi objeto desses decretos. Elas podiam também adotar quatro formatos diferentes: univerisdades; centros universitários; faculdades integradas; faculdades; institutos superiores ou escolas superiores. A Esses poderia ser adicionado o formato peculiar dos centros de educação tecnológica. Não se distinguiram faculdades, institutos nem escolas, termos que, em nosso país, têm sido utilizados arbitrariamente. (p. 807)

Os diferentes formatos organizativos do ensino superior, possibilitados pela última $\mathrm{LDB}$, deram-se sem dúvida no sentido de atender à diversidade dos interesses de mercado.

A privatização do ensino superior foi acelerada no octênio FHC. O número de instituições privadas aumentou consideravelmente, em especial na categoria universidades e nas dos centros universitários o que resultou na ampliação do alunado abrangido pelo setor. Tal crescimento fez-se com a complacência governamental diante da qualidade insuficiente do ensino ministrado nas instituições privadas a até mesmo com o benefício de credenciamento acadêmico e do crédito financeiro. (p. 807)

Para esse autor, a privatização sem precedentes do ensino superior na última década é fruto de um investimento que ele situa como parte de várias vertentes, entre elas, a implantação em não longo espaço de tempo em um modelo de ensino superior à semelhança do que ocorre nos Estados Unidos, que incorpora a regulação de mercado em substituição à regulação do Estado. Os estudantes "os consumidores" da mercadoria daí proveniente fariam a avaliação de sua qualidade, como acontece no universo empresarial. As características dessa vertente já podem ser percebidas claramente por aqueles que desenvolvem atividades docentes, discentes e administrativas em instituições privadas.

${ }^{23}$ A Lei 9394/96. 


\section{À guisa de considerações finais}

Isso posto, importa retomar interfaces que podem ser estabelecidas entre a educação escolar historicamente construída, levando em conta o modo como ela foi idealizada e posta em prática por um segmento minoritário da população em direção, à sua maioria, e aquela tida como representante desta em se tratando de sociedade pretensamente democrática. Compor e efetivar uma sociedade de fato democrática, todavia, tem sido ainda uma questão que estamos buscando construir. Ora de modo consciente, ora inconsciente, quando despertamos para certas condições objetivas nas quais nos encontramos. Quando deixamos de ser massa de manobra, quando simplesmente não pudemos captar os condicionamentos aos quais somos submetidos ao longo de nossa história.

Esse percurso histórico da educação brasileira não teve a pretensão de ser feito de modo exaustivo e minucioso. Ao contrário, ele serviu apenas para assinalar um dado que é perceptível em qualquer abordagem dessa natureza: o fato de que a educação escolar brasileira, quer seu nível básico quer superior, nunca foi um projeto de natureza eminentemente social. Enquanto interesse do Estado, ela foi e tem sido objeto de barganhas políticas e interesses imediatistas por parte daqueles que, de modo geral, no campo político partidário dela, tem-se utilizado como meio de auferir vantagens nesse domínio. Esse posicionamento nos remete à seguinte indagação: Se ela não tem sido preocupação política como uma questão social, seria de direito? Levando em conta que estamos juridicamente num estado de direito, forma na qual se organizou o Estado moderno. A resposta seria também não. Ela foi e tem sido vinculada a interesses mercantilistas quando da colonização e mercadológicos quando pensada em relação ao desenvolvimento e modernização do Brasil. Nunca como fator de ordem exclusivamente social, condição para que a população pudesse a ela ter acesso não como um direito simplesmente, mas uma questão intrínseca à natureza e desenvolvimento humano.

Por ter sido não um direito jamais atendido historicamente em sua plenitude, temos que reivindicá-la a todo o momento. Quer quando os segmentos trabalhadores clamam por vagas, quer quando essas mesmas vagas são concessões sob a justificativa do Estado de que fazem parte de política de inclusão. Deste modo, o que é direito torna-se consentimento do Estado, e por essa via constatamos o que disse certa vez Gilberto Dimestain (1993), que não temos cidadania por ser ela apenas de papel. Enquanto construto histórico, ela tem sido, de maneira geral, mecanismo de dominação e de opressão e, por assim dizer, elemento a merecer a atenção por parte daqueles que tomam para si a tarefa de fazer leis e de viabilizá-las. Principalmente no sentido de tornar concreto princípio de igualdade de oportunidades, ainda que a sociedade brasileira esteja composta por uma estrutura desigual. 


\section{Referências}

AZANHA, J. M. P. et al. Planos e políticas de educação no Brasil: alguns pontos para reflexão. In: AZANHA, J. M. P. et al. Estrutura e funcionamento da educação básica. São Paulo: Thomson, 1998.

BENCOSTA, M. L. A. Arquitetura e Espaço Escolar: reflexões acerca do processo de implantação dos Grupos Escolares de Curitiba (1903-1928). Educar em Revista. Curitiba, n. 18, p. 103-139, 2001.

BOURDIEU, P. O Poder simbólico. Rio de Janeiro: Bertrand Brasil, S.A, 1989. BRANDÃO, C. R. O Que é Educação. São Paulo: Brasiliense, 1989.

FREITAG, B. Escola, estado e sociedade. 3. ed. São Paulo: Cortez, 1979.

FREIRE, P. Pedagogia do Oprimido. Rio de Janeiro: Paz e Terra, 1987.

COVRE, M. L. M. A Fala dos Homens: análise do pensamento tecnocrático 1964-1981. São Paulo: Brasiliense, 1983.

CARVALHO, J. M. de. A Construção da Ordem: a elite política imperial; Teatro de sombras: a política imperial. Rio de Janeiro: UFRJ, Relume-Dumará, 1996.

CUNHA, L A. A Universidade Temporã: da colônia a era de Vargas. Rio de Janeiro: Francisco Alves, 1986.

. Ensino Superior e Universidade no Brasil. In: LOPES, E. M. T.; FARIA FILHO, L. M. de; VEIGA, C. G. (Orgs.). 500 anos de educação no Brasil. Belo Horizonte: Autêntica, 2000.

. A Universidade Critica: o ensino superior na república populista. Rio de Janeiro: Francisco Alves, 1983.

CUNHA, L. A. A universidade reformanda. Rio de Janeiro: F. Alves, 1985.

. Desenvolvimento desigual e combinado no ensino superior - estado e mercado. In: Revista Educação e Sociedade. Campinas, vol. 24, n. 88, p. 795817, Especial, Out. 2004.

DALLARI, D. de A. A República dos Oligarcas. In: Revista USP, n. 3, p. 13-18 set./out./nov. 1989.

DIMENSTEIN, Gilberto. O cidadão de papel: a infância, a adolescência e os direitos humanos no Brasil. 2 ed. São Paulo: Ática, 1993.

GERMANO, J. W. Estado Militar e Educação no Brasil 1964- 1985. São Paulo: Cortez,1994. 
HORTA, José Silvério Baia. Liberalismo, tecnocracia e planejamento educacional no Brasil: uma contribuição à história da educação brasileira no período 1930-1970. São Paulo: Cortez, 1982

NASCIMENTO, T. Q. R. do. Pedagogialiberal modernizadora. Campinas: FE/ UNICAMP, 1997.

PAIVA, J. M. de. Educação jesuíta no Brasil colonial. In: LOPES, E. M. T.; FARIA FILHO, L. M. de; VEIGA, C. G. (Orgs.). 500 anos de educação no Brasil. Belo Horizonte: Autêntica, 2000.

PAIVA, José Maria de. Colonização e Catequese: 1549-1600. São Paulo: Cortez, 1982;

RIBEIRO, Maria Luisa. História da Educação Brasileira: a organização escolar. São Paulo: Cortez, 1979

SAVIANI, Dermeval. Educação: do senso comum à consciência filosófica. São Paulo: Autores Associados, 1986.

SOUZA, Rosa Fátima de. Templos de Civilização: a implantação da escola primária graduada no estado de São Paulo (1890-1910). São Paulo: UNESP, 1998.

XAVIER, Maria Elizabete S. P. Poder político e educação de elite. São Paulo: Cortez, 1990. 